\title{
Behavior Factors and Temperament in Children with and without Early Childhood Caries: A Comparative Study
}

\author{
Fabiana Sodré de Oliveira ${ }^{1}$, Jillian Stefanie DM de AT Curtt e Silva ${ }^{2}$, Laysla Sabriene de Fátima Mendes ${ }^{2}$, \\ Danielly Cunha Araújo Ferreira ${ }^{1^{\star}}$, Marcelo Tavares ${ }^{3}$ and Alessandra de Maia de Castro ${ }^{1}$ \\ ${ }^{1}$ Professor of Pediatric Dentistry, School of Dentistry, Federal University of Uberlândia, Uberlândia, Minas \\ Gerais, Brazil \\ ${ }^{2}$ Graduate in Dentistry, School of Dentistry, Federal University of Uberlândia, Uberlândia, Minas Gerais, Brazil \\ ${ }^{3}$ Professor of Department of Applied Statistics, Faculty of Mathematics, Federal University of Uberlândia, \\ Uberlândia, Minas Gerais, Brazil
}

*Corresponding author: Danielly Cunha Araújo Ferreira, Department of Pediatric Dentistry, School of Dentistry, Federal University of Uberlândia, Av. Pará, s/n, Campus Umuarama, Uberlândia, Minas Gerais, Brazil, Tel: +55 3432258146; E-mail: danielly@ufu.br

Received Date: 09 September, 2017; Accepted Date: 07 November, 2017; Published Date: 22 November, 2017

\begin{abstract}
The aims of this study were to evaluate and to compare the behavioral risk factors (diet and oral hygiene habits) and temperament of children with and without early childhood caries assisted by public health service. A cross-sectional study was carried out with a convenience sample composed of 120 children of both gender aged two to five years and their respective mothers, divided into two groups. Two researches applied a questionnaire in order to obtain data about mother, family and child. Child temperament was classified according mother's perception, six choices of temperament were given to mothers and was asked to choose the most applicable to child: (1) calm; (2) fussy; (3) crying; (4) demanding; (5) stubborn; (6) other.Clinical examinations were carried out for the diagnosis of dental caries by the same trained and calibrated examiner for all subjects; the criteria of the World Health Organization were used for the diagnosis of dental caries. The presence of visible dental biofilm was evaluated on the vestibular surface of four upper incisors, without disclosing. The logistic regression $(\mathrm{p}<0.05)$ between children without caries and with early childhood caries showed that factors as the child age $(\mathrm{OR}=1.480)$, the frequency of sugar intake between meals $(\mathrm{OR}=2.343)$, use of fluoridated paste $(\mathrm{OR}=2.763)$, lack of brushing after dinner $(\mathrm{OR}=0.539)$ and unsatisfactory oral hygiene $(\mathrm{OR}=3.449)$ were associated to early childhood caries. There was no difference regarding the temperament of children with and without caries. Behavioral risk factors (dietary habits and oral hygiene) were associated with the presence of early childhood caries.
\end{abstract}

\section{Keywords}

Child; Dental Caries; Preschool: Risk Factors; Temperament

\section{Introduction}

Early Childhood Caries (ECC) is a common chronic disease of childhood, represents a significant public health problem [1] and has a negative impact on the oral health-related quality of life of preschool children, their parents [2,3] and the health system [4].The incidence of ECC is not uniformly distributed in a child population. It is confined to a subset of the total population of children. Therefore, identifying those at risk for developing the disease is a sound public health and private practice strategy [5].ECC has a complex etiology with biological, behavioural, and sociodemographic influences [6] and is resulting from an imbalance of multiple risk and protective factors over time [1]. Especially in young children, the list of factors that may directly or indirectly influence caries risk is extensive [7]. In a systematic review [8], 106 risk factors were found to be significantly related to the prevalence or incidence of dental caries in young children. In the last years, several risk factors for ECC have been extensively studied [9-24] and many studies have shown that behavioral risk factors (dietary habits and oral hygiene) are strongly associated to ECC [9-14,17-22]. Another risk factor that may have behavioral manifestations is the child temperament, since those considered of difficult temperament present a greater risk for the development of ECC [25-30]. Few studies have evaluated the relationship between child temperament as a risk factor 
Citation: de Oliveira FS, de Arruda Curtt e Silva JSDM, de Fátima Mendes LS, Ferreira DCA, Tavares M, et al. (2017) Behavior Factors and Temperament in Children with and without Early Childhood Caries: A Comparative Study. J Dent Sci Res Ther 2017: 30-36.

DOI :https://doi.org/10.29199/2637-7055/DSRT.101014.

for early childhood caries [25-32]. According with one study, the temperament of children with ECC was less sociable, energetic, rhytimic and highly distracted as compared to children without ECC [30]. Another study showed that [25], shyness, a subscale of Emotionality, Sociability, Activity (EAS) Temperament Survey for Children, and duration of feeding habit together were associated with ECC. The results of study by Aminabadi et al., [29] showed that in children with ECC, six aspects of temperament among 18 evaluated were significantly higher compared with children without ECC. Evidence suggests that child temperament reported by mothers may be related to important ECC risk factors [26]. Therefore, the objectives of this study were to evaluate and to compare the behavioral risk factors (diet and oral hygiene habits) and temperament of children with and without ECC assisted by public health service.

\section{Methodology}

\section{Ethicalprocedures}

The study was submitted and approved by the Research Ethics Committee of the Federal University of Uberlândia (Register number 735.009). The goals of the study were explained to the parents or primary caregivers and their written informed consent was taken.

\section{Study design and population}

A cross-sectional study was carried out with a convenience sample composed of 120 children of both gender aged two to five years and their respective mothers, divided into two groups, Group 1:60 children without ECC and Group 2:60 children with ECC. The children were selected among the patients attending the same Children's Dental Clinic in a public health service, who presented as following inclusion criteria: gestational age $\geq 37$ weeks; birth weight $\geq 2.500$; children who were born and lived in the city since birth; complete mental and physical health, and mothers with similar age ( $\geq 24$ years), educational and socioeconomic levels.

\section{Data collection}

Two researchers applied a questionnaire in order to obtain data about mother (status marital and employment), family (parents live together, monthly household income and number of people in residence) and child (age, number of siblings, birth position, diet and oral hygiene habits, use of dental floss and temperament).

\section{Mother's perception of child temperament}

Six choices of temperament were given to mothers and was asked to choose the most applicable to child: (1) calm; (2) fussy; (3) crying; (4) demanding; (5) stubborn; (6) other. The temperament of the child was classified as easy if the mother chose the option (1) calm or difficult if she chose the options (2) fussy, (3) crying, (4) demanding and (5) stubborn. When the mother's choice was (6) other, the children was classified by the researcher's judgment. For example, if a mother answered happy, she was classified as easy. On the other hand, is a mother answered grumpy, she was classified as difficult [26].

\section{Clinical examination}

All clinical examinations were carried out with a dental mirror and an explorer by the same trained and calibrated examiner for all subjects $(\mathrm{k}=0.98)$. Oral hygiene quality was evaluated based on presence of visible dental biofilm on the vestibular surface of four upper incisors, without disclosing. The criteria of the World Health Organization [33] were used for the diagnosis of dental caries.

\section{The dependent variable and the exposures of inter- est}

The dependent variable was the presence of ECC and the exhibition of interest was the temperament of the child.

\section{Statisticalanalysis}

The data were tabulated and analysed by using SPSS Statistics (IBM, Inc, Chicago, Illinois, USA) version 17. Associations between ECC and independent variables were determined using the multiple logistic regression model. The dependent variable was the absent and presence of ECC. OddsRatio (O.R.) for each of the variables was calculated and the confidence interval was set at $95 \%$ and the value of $p \leq 0.05$.

\section{Results}

ECC experience was expressed as absent or present. Relations between variables related to mother, to the family and to the child, diet and oral hygiene habits and mother's perception of child temperament and absent and presence of ECC were showed in (Tables 1-4) respectively. The mean (DMFT) value was 2.95. The mean ages of children without caries and who presented caries were respectively, 2.75 years (standard desviation: 2.82 years) and 3.35 years (standard desviation $=2.12$ years) Table 1 .

ECC was significantly associated with age $(p=0.035)$, intake of sugar with and after main meals $(p=0.003)$, use of dentifrice fluoride $(\mathrm{p}=0.013)$, person that brushing after dinner $(0.047)$ and presence of visible dental biofilm $(p=0.001)$. Older children, who did not use fluoridated toothpaste, with high frequency of sugar intake with and after main meals, showed an increase in 2.763 and 2.342 times more likely to have ECC, respectively. The lack of brushing after dinner increased the chance of the child showed ECC in 0.539 times and the unsatisfactory oral hygiene increased the probability of a child presenting ECC in 3.449 times (Table 5). 
Citation: de Oliveira FS, de Arruda Curtt e Silva JSDM, de Fátima Mendes LS, Ferreira DCA, Tavares M, et al. (2017) Behavior Factors and Temperament in Children with and without Early Childhood Caries: A Comparative Study. J Dent Sci Res Ther 2017: 30-36.

\begin{tabular}{|c|c|c|c|c|c|c|c|}
\hline \multirow{2}{*}{ Variables } & Absent & Presence & Total & \multirow{2}{*}{ Variables } & Absent & Presence & Total \\
\hline & n (\%) & n (\%) & n (\%) & & n (\%) & n (\%) & n (\%) \\
\hline \multicolumn{4}{|c|}{ Parents marital status } & \multicolumn{4}{|c|}{ Breastfeeding (months) } \\
\hline Single & $13(10.8)$ & $16(13.3)$ & $29(24.2)$ & Never used & $2(1.7)$ & $3(2.5)$ & $5(4.2)$ \\
\hline Married & $46(38.3)$ & $41(34.2)$ & $87(72.5)$ & Until 6 & $19(15.8)$ & $14(11.7)$ & $33(27.5)$ \\
\hline Widow & $1(0.8)$ & $1(0.8)$ & $2(1.7)$ & $7-12$ & $16(13.3)$ & $9(7.5)$ & $25(20.8)$ \\
\hline Divorced & $0(0.0)$ & $2(1.7)$ & $2(1.7)$ & $13-18$ & $4(3.3)$ & $6(5.0)$ & $10(8.3)$ \\
\hline Parents employment & $10(8.3)$ & $17(14.2)$ & $27(22.5)$ & $19-24$ & $10(8.3)$ & $17(14.2)$ & $27(22.5)$ \\
\hline No & $29(24.2)$ & $30(25.0)$ & $59(49.2)$ & $\geq 25$ & $4(3.3)$ & $4(3.3)$ & $8(6.7)$ \\
\hline Yes & $31(25.8)$ & $30(25.0)$ & $61(50.8)$ & Yes, still breastfeeding & $5(4.2)$ & $7(5.8)$ & $12(10.0)$ \\
\hline \multicolumn{4}{|c|}{ Parents live together } & \multicolumn{4}{|c|}{ Breastfeeding (times/day) } \\
\hline No & $10(8.3)$ & $11(9.2)$ & $21(17.5)$ & 1 & $1(0.8)$ & $1(0.8)$ & $2(1.7)$ \\
\hline Yes & $50(41.7)$ & $49(40.8)$ & $99(82.5)$ & 2 & $0(0.0)$ & $2(1.7)$ & $2(1.7)$ \\
\hline \multirow{2}{*}{$\begin{array}{l}\text { Monthly household in- } \\
\text { come }\end{array}$} & \multirow{2}{*}{$1(0.8)$} & \multirow{2}{*}{$1(0.8)$} & \multirow{2}{*}{$2(1.7)$} & 3 & $1(0.8)$ & $1(0.8)$ & $2(1.7)$ \\
\hline & & & & 4 & $0(0.0)$ & $1(0.8)$ & $1(0.8)$ \\
\hline \multirow{2}{*}{$\begin{array}{c}<2 \text { times the minimum } \\
\text { wage }\end{array}$} & \multirow[t]{2}{*}{$8(6.7)$} & \multirow[t]{2}{*}{$10(8.3)$} & \multirow[t]{2}{*}{$18(15.0)$} & 5 & $1(0.8)$ & $2(1.7)$ & $3(2.5)$ \\
\hline & & & & \multicolumn{4}{|c|}{ Use of bottle (months) } \\
\hline $\begin{array}{l}\geq 2 \text { times the minimum } \\
\text { wage }\end{array}$ & $49(37.8)$ & $46(38.3)$ & $95(76.1)$ & Never used & $9(7.5)$ & $18(15.0)$ & $27(22.5)$ \\
\hline \multicolumn{4}{|c|}{ Number of people in residence } & Until 6 & $0(0.0)$ & $1(0.8)$ & $1(0.8)$ \\
\hline 2 & $3(2.5)$ & $2(1.7)$ & $5(4.2)$ & $7-12$ & $1(0.8)$ & $1(0.8)$ & $2(1.7)$ \\
\hline 3 & $26(21.7)$ & $18(15.0)$ & $44(36.7)$ & $13-18$ & $1(0.8)$ & $5(4.2)$ & $6(5.0)$ \\
\hline 4 & $22(18.3)$ & $23(19.2)$ & $45(37.5)$ & $19-24$ & $7(5.8)$ & $6(5.0)$ & $13(10.8)$ \\
\hline 5 & $7(5.8)$ & $12(10.0)$ & $19(15.8)$ & $\geq 25$ & $5(4.2)$ & $6(5.0)$ & $11(9.2)$ \\
\hline$\geq 6$ & $2(1.7)$ & $5(4.2)$ & $7(5.8)$ & Yes, still breastfeeding & $37(30.8)$ & $23(19.2)$ & $60(50.0)$ \\
\hline \multicolumn{4}{|c|}{ Age of children (years) } & \multicolumn{4}{|c|}{$\begin{array}{l}\text { Use of bottle (times/day) } \\
\end{array}$} \\
\hline 2 & $35(29.2)$ & $22(18.3)$ & $57(47.5)$ & 0 & $22(18.3)$ & $36(30.0)$ & $58(48.3)$ \\
\hline 3 & $11(9.2)$ & $10(8.3)$ & $21(17.5)$ & 1 & $6(5.0)$ & $5(4.2)$ & $11(9.2)$ \\
\hline 4 & $8(6.7)$ & $13(10.8)$ & $21(17.5)$ & 2 & $15(12.5)$ & $8(6.7)$ & $23(19.2)$ \\
\hline 5 & $6(5.0)$ & $15(12.5)$ & $21(17.5)$ & 3 & $13(10.8)$ & $8(6.7)$ & $21(17.5)$ \\
\hline \multicolumn{4}{|c|}{ Number of siblings } & 4 & $1(0.8)$ & $1(0.8)$ & $2(1.7)$ \\
\hline None & $23(19.2)$ & $18(15.0)$ & $41(34.2)$ & 5 & $2(1.7)$ & $1(0.8)$ & $3(2.5)$ \\
\hline 1 & $28(23.3)$ & $24(20.0)$ & $52(43.3)$ & $\geq 6$ & $1(0.8)$ & $1(0.8)$ & $2(1.7)$ \\
\hline 2 & $9(7.5)$ & $14(11.7)$ & $23(19.2)$ & \multicolumn{4}{|c|}{ Product with sugar in bottle } \\
\hline 3 & $0(0.0)$ & $2(1.7)$ & $2(1.7)$ & No & $15(12.5)$ & $16(13.3)$ & $31(25.8)$ \\
\hline$\geq 4$ & $0(0.0)$ & $2(1.7)$ & $2(1.7)$ & Yes & $45(37.5)$ & $44(36.7)$ & $89(74.2)$ \\
\hline \multicolumn{4}{|c|}{ Position of child birth } & \multicolumn{4}{|c|}{ Take a botlle to sleep } \\
\hline First & $26(21.7)$ & $22(18.3)$ & $48(40.0)$ & No & $19(15.8)$ & $25(20.8)$ & $44(36.7)$ \\
\hline Second & $29(24.2)$ & $29(24.2)$ & $58(48.3)$ & Yes & $41(34.2)$ & $35(29.2)$ & $76(63.3)$ \\
\hline Third & $4(3.3)$ & $7(5.8)$ & $11(9.2)$ & & Wake up to & rse & \\
\hline Fourth & $1(0.8)$ & $1(0.8)$ & $2(1.7)$ & Never & $53(44.2)$ & $56(46.7)$ & $109(90.8)$ \\
\hline Other & $0(0.0)$ & $1(0.8)$ & $1(0.8)$ & Yes, sometimes & $6(5.0)$ & $1(0.8)$ & $7(5.8)$ \\
\hline \multirow{2}{*}{\multicolumn{4}{|c|}{$\begin{array}{l}\text { Table 1: Relation between variables related to mother, to the family } \\
\text { and to the child and absent and presence of ECC. }\end{array}$}} & Yes, always & $1(0.8)$ & $3(2.5)$ & $4(3.3)$ \\
\hline & & & & \multicolumn{4}{|c|}{ Intake of sugar with and after main meals (times/day) } \\
\hline
\end{tabular}


Citation: de Oliveira FS, de Arruda Curtt e Silva JSDM, de Fátima Mendes LS, Ferreira DCA, Tavares M, et al. (2017) Behavior Factors and Temperament in Children with and without Early Childhood Caries: A Comparative Study. J Dent Sci Res Ther 2017: 30-36.

\begin{tabular}{|l|l|l|l|}
\hline Unless 1 & $30(25.0)$ & $14(11.7)$ & $44(36.7)$ \\
\hline $1-2$ & $16(13.3)$ & $24(20.0)$ & $40(33.3)$ \\
\hline$\geq 3$ & $14(11.7)$ & $22(18.3)$ & $36(30.0)$ \\
\hline \multicolumn{4}{|l|}{ Intake of sugar between main meals (times/day) } \\
\hline Unless 1 & $30(25.0)$ & $28(23.3)$ & $58(48.3)$ \\
\hline 2 & $23(19.2)$ & $22(18.3)$ & $45(37.5)$ \\
\hline$\geq 3$ & $7(5.8)$ & $10(8.3)$ & $17(14.2)$ \\
\hline
\end{tabular}

Table 2: Relation between Diet Habits and Absent and Presence of ECC.

\begin{tabular}{|c|c|c|c|}
\hline Variables & Absentn (\%) & Presencen (\%) & Totaln (\%) \\
\hline $\begin{array}{l}\text { Start dental child } \\
\text { brushing }\end{array}$ & $16(13.3)$ & $24(20.0)$ & $40(33.3)$ \\
\hline $\begin{array}{l}\text { Before dental erup- } \\
\text { tion }\end{array}$ & $48(40.0)$ & $39(32.5)$ & $87(72.5)$ \\
\hline $\begin{array}{l}\text { After eruption of } \\
\text { incisors }\end{array}$ & $12(10.0)$ & $21(17.5)$ & $33(27.5)$ \\
\hline $\begin{array}{l}\text { Child dental brush- } \\
\text { ing (times/day) }\end{array}$ & $30(25.0)$ & $28(23.3)$ & $58(48.3)$ \\
\hline 1 & $6(5.0)$ & $5(4.2)$ & $11(9.2)$ \\
\hline 2 & $25(20.8)$ & $24(20.0)$ & $49(40.8)$ \\
\hline 3 & $26(21.7)$ & $27(22.5)$ & $53(44.2)$ \\
\hline 4 & $3(2.5)$ & $4(3.3)$ & $7(5.8)$ \\
\hline \multicolumn{4}{|c|}{ Use of fluoride dentifrice by the child } \\
\hline No & $37(30.8)$ & $22(18.3)$ & $59(49.2)$ \\
\hline Yes & $23(19.2)$ & $38(31.7)$ & $61(50.8)$ \\
\hline \multicolumn{4}{|c|}{ Person brushing after breakfast } \\
\hline Nobody & $8(6.7)$ & $6(5.0)$ & $14(11.7)$ \\
\hline Mother/Father & $47(39.2)$ & $42(35.0)$ & $89(74.2)$ \\
\hline Child & $0(0.0)$ & $8(6.7)$ & $8(6.7)$ \\
\hline Other & $5(4.2)$ & $4(3.3)$ & $9(7.5)$ \\
\hline \multicolumn{4}{|c|}{ Person brushing after lunch } \\
\hline Nobody & $22(18.3)$ & $19(15.8)$ & $41(34.2)$ \\
\hline Mother/Father & $24(20.0)$ & $20(16.7)$ & $44(36.7)$ \\
\hline Child & $4(3.3)$ & $9(7.5)$ & $13(10.8)$ \\
\hline Other & $10(8.3)$ & $12(10.0)$ & $22(18.3)$ \\
\hline \multicolumn{4}{|c|}{ Person brushing after dinner } \\
\hline Nobody & $32(26.7)$ & $39(32.5)$ & $71(59.2)$ \\
\hline Mother/Father & $22(18.3)$ & $18(15.0)$ & $40(33.3)$ \\
\hline Child & $2(1.7)$ & $2(1.7)$ & $4(3.3)$ \\
\hline Other & $4(3.3)$ & $1(0.8)$ & $5(4.2)$ \\
\hline \multicolumn{4}{|c|}{ Person brushing before bed } \\
\hline Nobody & $20(16.7)$ & $19(15.8)$ & $39(32.5)$ \\
\hline Mother/Father & $36(30.0)$ & $38(31.7)$ & $74(61.7)$ \\
\hline Child & $1(0.8)$ & $2(1.7)$ & $3(2.5)$ \\
\hline
\end{tabular}

\begin{tabular}{||c|c|c|c|}
\hline Other & $3(2.5)$ & $1(0.8)$ & $4(3.3)$ \\
\hline \multicolumn{4}{|c|}{ Use of dental floss by the child } \\
\hline No & $21(17.5)$ & $22(18.3)$ & $43(35.8)$ \\
\hline Yes & $39(32.5)$ & $38(31.7)$ & $77(64.2)$ \\
\hline \multicolumn{4}{|c|}{ Oral hygiene } \\
\hline No & $39(32.5)$ & $21(17.5)$ & $60(50.0)$ \\
\hline Yes & $21(17.5)$ & $39(32.5)$ & $60(50.0)$ \\
\hline
\end{tabular}

Table 3: Relation between Diet Habits and Absent and Presence of ECC.

\begin{tabular}{|c|c|c|c|}
\hline Variables & Absentn (\%) & Presencen (\%) & Totaln (\%) \\
\hline Calm & $15(12.5)$ & $13(10.8)$ & $28(23.3)$ \\
\hline Fussy & $13(10.8)$ & $18(15.0)$ & $31(25.8)$ \\
\hline Crying & $8(6.7)$ & $8(6.7)$ & $16(13.3)$ \\
\hline Demanding & $14(11.7)$ & $10(8.3)$ & $24(20.0)$ \\
\hline Stubborn & $9(7.5)$ & $10(8.3)$ & $19(15.8)$ \\
\hline Other & $1(0.8)$ & $1(0.8)$ & $2(1.7)$ \\
\hline \multicolumn{5}{|c|}{ Temperament } \\
\hline Difficult & $44(36.6)$ & $46(38.4)$ & $90(75.0)$ \\
\hline Easy & $16(13.3)$ & $14(11.7)$ & $30(25.0)$ \\
\hline
\end{tabular}

Table 4: Relation between Mother's Perception of Child Temperament and Absent and Presence of ECC.

"ECC was significantly associated with age $(p=0.035)$, intake of sugar with and after main meals $(p=0.003)$, use of dentifrice fluoride $(\mathrm{p}=0.013)$, person that brushing after dinner $(0.047)$ and presence of visible dental biofilm $(\mathrm{p}=0.001)$. Older children, who did not use fluoridated toothpaste, with high frequency of sugar intake with and after main meals, showed an increase in 2.763 and 2.342 times more likely to have ECC, respectively. The lack of brushing after dinner increased the chance of the child showed ECC in 0.539 times and the unsatisfactory oral hygiene increased the probability of a child presenting ECC in 3.449 times (Table 5)."

\begin{tabular}{|l|c|c|c|c|}
\hline \multicolumn{1}{|c|}{ Variables } & P-value & OR & \multicolumn{2}{c|}{ 95\%CI } \\
\hline Marital status & 0.512 & 1.333 & 0.565 & 3.145 \\
\hline Employment & 0.715 & 1.177 & 0.49 & 2.827 \\
\hline Parents live together & 0.863 & 0.906 & 0.296 & 2.773 \\
\hline $\begin{array}{l}\text { Monthly household in- } \\
\text { come }\end{array}$ & 0.158 & 0.755 & 0.511 & 1.115 \\
\hline $\begin{array}{l}\text { Number of people in res- } \\
\text { idence }\end{array}$ & 0.222 & 1.411 & 0.813 & 2.45 \\
\hline Age of children & $0.035^{*}$ & 1.48 & 1.029 & 2.129 \\
\hline Number of siblings & 0.257 & 1.765 & 0.66 & 4.719 \\
\hline Birth position & 0.505 & 0.677 & 0.215 & 2.131 \\
\hline Breastfeeding & 0.972 & 0.995 & 0.748 & 1.324 \\
\hline
\end{tabular}


Citation: de Oliveira FS, de Arruda Curtt e Silva JSDM, de Fátima Mendes LS, Ferreira DCA, Tavares M, et al. (2017) Behavior Factors and Temperament in Children with and without Early Childhood Caries: A Comparative Study. J Dent Sci Res Ther 2017: 30-36.

\begin{tabular}{|l|c|c|c|c|}
\hline Times/day & 0.537 & 1.187 & 0.689 & 2.043 \\
\hline Use of bottle & 0.186 & 0.842 & 0.652 & 1.086 \\
\hline Times/day & 0.708 & 0.931 & 0.64 & 1.353 \\
\hline $\begin{array}{l}\text { Product with sugar in } \\
\text { bottle }\end{array}$ & 0.56 & 1.354 & 0.489 & 3.754 \\
\hline Take a bottle to sleep & 0.508 & 0.732 & 0.291 & 1.842 \\
\hline Wake up to nurse & 0.227 & 0.426 & 0.107 & 1.699 \\
\hline $\begin{array}{l}\text { Intake of sugar with and } \\
\text { after main meals }\end{array}$ & $0.003 *$ & 2.342 & 1.332 & 4.116 \\
\hline $\begin{array}{l}\text { Intake of sugar between } \\
\text { main meals }\end{array}$ & 0.784 & 0.918 & 0.497 & 1.695 \\
\hline Start of teeth brushing & 0.199 & 1.808 & 0.733 & 4.46 \\
\hline Times/day & 0.888 & 1.042 & 0.587 & 1.849 \\
\hline Use of fluoride dentifrice & $0.013 *$ & 2.763 & 1.24 & 6.157 \\
\hline Brushing after breakfast & 0.519 & 1.213 & 0.675 & 2.18 \\
\hline Brushing after lunch & 0.14 & 1.388 & 0.898 & 2.145 \\
\hline Brushing after dinner & $0.047 *$ & 0.539 & 0.293 & 0.992 \\
\hline Brushing before bed & 0.219 & 0.65 & 0.327 & 1.292 \\
\hline Use of dental floss & 0.934 & 0.966 & 0.428 & 2.182 \\
\hline Oral hygiene & $0.001 *$ & 3.449 & 1.629 & 7.303 \\
\hline Temperament & 0.324 & 0.675 & 0.309 & 1.474 \\
\hline$*$ p $<0.05)$ & & & \\
\hline Table $:$ Descipton of the Statical & analses & $0 f$ \\
\hline
\end{tabular}

Table 5: Description of the Statistical Analyses of Multiple Logistic Regression.

\section{Discussion}

In the present study, the child temperament was evaluated as possible indicator of risk of ECC. However, the results showed no relationship between the type of temperament easy or difficult and the absence and presence of ECC. This finding is in disagreement with other studies [25-32] and in accordance with the study by Kendrick et al. [31]. Some limitations should be mentioned, such as the selection and sample size, the selected sample was of convenience and compared to other cross-sectional studies the sample size was lower [10-16,19-21,26-32]. However, despite the small sample size, the mothers and the children presented similar characteristics considered as risk factors related to ECC [6,7,10,12-16,19]. Mother's age, socioeconomic and educational levels were similar between the groups. In addition, the children presented characteristics similar to birth, age group and access to dental care from the first appointment in a public service. Considering that these children showed population determinants at risk for ECC, this study evaluated and compared behavioral risk factors and temperament among children with and without ECC. Clinical examinations were performed using the World Health Organization criteria, the number of erupted teeth was not evaluated and this fact can be considered as a limitation of the present study, since the number of erupted teeth may be different in both groups. Another limitation is the study design it is known that accurate caries risk assessment at the population level is both desirable and achievable based on high-quality longitudinal studies [4]. Nevertheless, few studies are longitudinal design $[17,18,22,24]$. In dentistry, parent-report measures have been used to predict behaviors and ECC in children [25]. Several tools can be used as EAS Temperament Survey for children [25], NYLS Temperament Scale [27], Behavioral Survey [28], Early Childhood Behavior Questionnaire [29], Toddler Temperament Scale [31], and other approaches [26,32]. In this study, the temperament of the child was evaluated according to the mothers' perception and classified in easy and difficult temperament as in the study of Spitzet al. [26]. Although the other tools assess more aspects of child temperament, the scales have not yet been adapted for use in Brazilian children, and for this reason were not used. The child temperament is considered stable over time and has been considered as a risk factor for caries because it can influence the mothers' reactions. Children classified as difficult were more likely to be bottle-fed to sleep [26]. In other study [25], duration of feeding habit and shyness together were associated with ECC. In present study, no difference was observed between the use of bottle in children with and without caries. In this study, the average age in the group of children with ECC was higher compared to the children of control group and ECC was significantly associated with age. This result is in agreement with findings related in other studies $[11,12,19,20]$. This can be explained by the fact that ECC is a cumulative process and develops over years [19]. Furthermore, ECC increased with increasing age, because there is an increasing number of erupted deciduous teeth, which become exposed to the oral environment and cariogenic challenge [20].Several studies [9,11,18,19,22,23,28] showed that the high frequency of intake of sugar represents a significant risk factor for ECC. In the present study ECC was significantly associated with intake of sugar with and after main meals. An associated risk factor of ECC is high consumption of sugars due to prolonged contact between sugars and cariogenic bacteria on the susceptible teeth [1].Current the best practice to reduce the risk of ECC includes brushing with fluoride dentifrice twice-daily [1]. In this study, ECC was significantly associated with use of fluoride dentifrice, lack of brushing after dinner and unsatisfactory oral hygiene, characterized by presence of visible dental biofilm. These factors are related to each other.With respect to use of fluoride dentifrice, result of this study disagreed with the obtained by Slabsinskiene et al., [32] that found no difference between children with and without ECC. In the present study the use of dental floss was evaluated, the parents being responsible for the use of dental floss by the child, and this device is used at least once a day. However, it was not found statistical relevance related to the use of dental floss and the beginning of the oral hygiene of the child and the presence od ECC. However, there was a relationship between the lack of brushing of parents after dinner with the ECC.According to a systematic review of the literature [8] there is evidence in the majority of studies that the brushing once a day or more, and the presence of visible dental biofilm are more important than other factors, such as the age at which the child initiated the brushing, parental 
Citation: de Oliveira FS, de Arruda Curtt e Silva JSDM, de Fátima Mendes LS, Ferreira DCA, Tavares M, et al. (2017) Behavior Factors and Temperament in Children with and without Early Childhood Caries: A Comparative Study. J Dent Sci Res Ther 2017: 30-36.

supervision, do not perform the brushing before bed and use of fluoridated toothpaste.Although, in the present study, there have been no significant differences between the child temperament of children without and with ECC, it must be considered that no factor operates in isolation, but in association with others. In a recent study, several potential barriers to good oral health practice, including child'stemperament and inability to control sugar intake were identified by parents and caregivers [34]. Therefore, further longitudinal studies are needed with regard to the theme.

\section{Conclusion}

The results of this study showed that factors such as the age of the child, the use of fluoride toothpaste, the person responsible for brushing after dinner, the frequency of sucrose intake after meals and the presence of dental biofilm were associated with the development of ECC, and therefore behavioral risk factors (dietary habits and oral hygiene) are associated with the presence of ECC. However, in this study there was no difference regarding the temperament of children with and without caries. It is necessary to carry out longitudinal studies to verify this association.

\section{References}

1. [No authors listed] (2016) Policy on Early Childhood Caries (ECC): Classifications, Consequences, and Preventive Strategies. Pediatr Dent 38: 52-54.

2. Martins-Júnior PA, Vieira-Andrade RG, Corrêa-Faria P, Oliveira-Ferreira F, Marques LS, et al. (2013) Impact of early childhood caries on the oral health-related quality of life of preschool children and their parents. Caries Res 47: 211-218.

3. Li MY, Zhi QH, Zhou Y, Qiu RM, Lin CH (2015) Impact of early childhood caries on oral health-relatedquality of life of preschool children. Eur J Paediatr Dent 16: 65-72.

4. Divaris K (2016) Predicting Dental Caries Outcomes in Children: A "Risky" Concept. J Dent Res 95: 248-254.

5. Anderson M (2002) Risk assessment and epidemiology of dental caries: review of the literature. Pediatr Dent 24: 377-385.

6. Arora A, Schwarz E, BlinkhornAS (2011) Risk factors for early childhood caries in disadvantaged populations. J Investig Clin Dent 2: 223-228.

7. Fontana M (2015) The Clinical, Environmental, and Behavioral Factors That Foster Early Childhood Caries: Evidence for Caries Risk Assessment. Pediatr Dent 37: 217-225.

8. Harris R, Nicoll AD, Adair PM, Pine CM (2004) Risk factors for dental caries in young children: a systematic review of the literature. Community Dent Health 21: 71-85.

9. Niji R, Arita K, Abe Y, Lucas ME, Nishino M, et al. (2010) Maternal age at birth and other risk factors in early childhood caries. Pediatr Dent 32: 493-498.

10. Ozer S, Sen Tunc E, Bayrak S, Egilmez T (2011) Evaluation of certain risk factors for early childhood caries in Samsun, Turkey. Eur J Paediatr Dent 12: 103-106.
11. Li Y, Zhang Y, Yang R, Zhang Q, Zou J, et al. (2011) Associations of social and behavioural factors with early childhood caries in Xiamen city in China. Int J Paediatr Dent 21: 103-111.

12. Corrêa-Faria $P$, Martins-Júnior PA, Vieira-Andrade RG, Marques LS, Ramos-Jorge ML, et al. ( 2013) Factors associated with the development of early childhood caries among Brazilian preschoolers. Braz Oral Res 27: 356-362.

13. Bissar A, Schiller P, Wolff A, Niekusch U, Schulte AG, et al. (2014) Factors contributing to severe early childhood caries in south-west Germany. Clin Oral Investig 18: 1411-1418.

14. Congiu G, Campus G, Sale S, Spano G, Cagetti MG, et al. (2014) Early childhood caries and associated determinants: a cross-sectional study on Italian preschool children. J Public Health Dent 74: 147-152.

15. Moimaz SA, Fadel CB, Lolli LF, Garbin CA, Garbin AJ, et al. (2014) Social aspects of dental caries in the context of mother-child pairs. J Appl Oral Sci 22: 73-78.

16. dos Santos Junior VE, de Sousa RM, Oliveira MC, de Caldas Junior AF, Rosenblatt A (2014) Early childhood caries and its relationship with perinatal, socioeconomic and nutritional risks: a cross-sectional study. BMC Oral Health 14: 47.

17. Chaffee BW, Feldens CA, Rodrigues PH, Vítolo MR (2015) Feeding practices in infancy associated with caries incidence in early childhood. Community Dent Oral Epidemiol 43: 338-348.

18. Ghazal T, Levy SM, Childers NK, Broffitt B, Cutter GR, et al. (2015) Factors associated with early childhood caries incidence among high caries-risk children. Community Dent Oral Epidemiol 43: 366374.

19. Jain M, Namdev R, Bodh M, Dutta S, Singhal P, et al. (2015) Social and Behavioral Determinants for Early Childhood Caries among Preschool Children in India. J Dent Res Dent Clin Dent Prospects 9: $115-120$.

20. Olatosi OO, Inem V, Sofola OO, Prakash P, Sote EO (2015) Theprevalenceofearlychildhoodcariesand itsassociatedrisk factorsamongpreschoolchildren referred to a tertiary care institution. $\mathrm{Ni}$ ger J Clin Pract 18: 493-501.

21. Özen B, van Strijp AJ, Özer L, Olmus H, Genc A, et al. (2016)Evaluation of possible associated factors for Early Childhood Caries and Severe Early Childhood Caries: A Multicenter Cross-Sectional Survey. J Clin Pediatr Dent 40: 118-123.

22. Paglia L, Scaglioni S, Torchia V, De Cosmi V, Moretti M, et al. (2016) Familial and dietary risk factors in early childhood caries. Eur J Paediatr Dent 17: 93-99.

23. Fan C, Wang W, Xu T, Zheng S (2016) Risk factors of early childhood caries among children in Beijing: a case-control study. BMC Oral Health 16: 98.

24. Bernabé E, MacRitchie H, Longbottom C, Pitts NB, Sabbah W (2017) Birth weight, Breastfeeding, Maternal Smoking and Caries Trajectories. J Dent Res 96: 171-178.

25. Quinonez R, Santos RG, Wilson S, Cross H (2001) The relationship between child temperament and early childhood caries. Pediatr Dent 23: 5-10.

26. Spitz AS, Weber-Gasparoni K, Kanellis MJ, Qian F (2006) Child temperament and risk factors for early childhood caries. J Dent Child 73: 98-104. 
Citation: de Oliveira FS, de Arruda Curtt e Silva JSDM, de Fátima Mendes LS, Ferreira DCA, Tavares M, et al. (2017) Behavior Factors and Temperament in Children with and without Early Childhood Caries: A Comparative Study. J Dent Sci Res Ther 2017: 30-36.

27. Zhao Y, Ge LH, Yu C, Liu Z, Wang YF (2006) [The relationship between early childhood caries and child temperament]. Zhonghua Kou Qiang Yi Xue Za Zhi41: 422-425.

28. Fierro Monti C, Pérez Flores M, Brunotto M (2014) Simple predictive model for early childhood caries of Chilean children. Rev FacCien Med UnivNac Cordoba 71: 105-112.

29. Aminabadi NA, Ghoreishizadeh A, Ghoreishizadeh M, Oskouei SG, Ghojazadeh M (2014) Can child temperament be related to early childhood caries? Caries Res 48: 3-12.

30. Jabin Z, Chaudhary S (2014) Association of child temperament with early childhood caries. J Clin Diagn Res 8: 21-24.

31. Kendrick F, Wilson S, Coury DL, Preisch JW (1998) Comparison of temperaments of children with and without baby bottle tooth decay. ASDC J Dent Child 65: 198-203.
32. Slabsinskiene E, Milciuviene S, Narbutaite J, Vasiliauskiene I, Andruskeviciene V, et al. (2010) Severe early childhood caries and behavioral risk factors among 3-year-old children in Lithuania. Medicina (Kaunas) 46: 135-141.

33. World Health Organization (2013) Oral Health Surveys: basic methods. 5thedn, World Health Organization, Geneva, Switzerland.

34. Prowse S, Schroth RJ, Wilson A, Edwards JM, Sarson J, et al. (2014)Diversity considerations for promoting early childhood oral health: A pilot study. Int J Dent2014: 1-10. 